Original Investigation

\title{
Surgical Site Infection and Its Associated Factors Following Obstetric Surgeries: A Retrospective Study
}

\author{
Ram Prasad Sharma G ${ }^{*}$, Laxmi Rajbanshi ${ }^{2}$, Basanta Thapa ${ }^{2}$, Jaya Prasad Singh ${ }^{3}$, Renuka Tamrakar ${ }^{4}$
}

\author{
${ }^{1}$ Department of Hospital Administration, Chitwan Medical College Teaching Hospital, Chitwan, Nepal. \\ ${ }^{2}$ School of Nursing, Chitwan Medical College Teaching Hospital, Chitwan, Nepal. \\ ${ }^{3}$ School of Public Health, Chitwan Medical College Teaching Hospital, Chitwan, Nepal. \\ ${ }^{4}$ School of Medicine and Allied Health Science, Chitwan Medical College Teaching Hospital, Chitwan, Nepal.
}

\author{
ARTICLE INFO \\ Article history: \\ Received: 17 March 2021 \\ Revised: 11 May 2021 \\ Accepted: 23 June 2021 \\ *Correspondence: \\ Ram Prasad Sharma G \\ Department of Hospital \\ Administration, Chitwan Medical \\ College Teaching Hospital. \\ E-mail: \\ sharmamha@gmail.com \\ Citation: \\ Sharma G RP, Rajbanshi L, Thapa \\ B, Singh JP, Tamrakar R. Surgical \\ Site Infection and Its Associated \\ Factors Following Obstetric \\ Surgeries: A Retrospective Study. \\ MedS. J. Med. Sci. 2021; 1(1):32-36
}

\begin{abstract}
ABSTARCT
INTRODUCTION: Surgical site infection (SSI) is most common type of Hospital Acquired Infection (HAI) in low and middle-income countries. The objective of the study was to find out the incidence and associated factors of SSI following obstetric surgeries especially Lower Segment Cesarean Section (LSCS). MATERIALS AND METHODS: A retrospective cross sectional study was conducted at Chitwan Medical College Teaching Hospital. A total of 1739 patients files who had undergone Lower Segment Cesarean Section from $14^{\text {th }}$ April 2019 to 12 April 2020 was reviewed. Data was analysed using IBM SPSS Version 20.0 and interpreted in descriptive and inferential statistics. RESULTS: Among 1739 obstetric surgeries performed, 50 patient showed signs and symptoms of SSI yielding to an infection rate of $2.9 \%$. Majority $(80 \%)$ of patients developed SSI after they were discharged. There was significant association between SSI and type of surgery $(p=0.007)$ and, SSI was not associated with haemoglobin level, blood transfusion, residence and age of the patients. CONCLUSIONS: Though overall infection rate was low, most of the women developed infection after being discharged, thus it is recommended that discharge counselling about wound care should be emphasized.
\end{abstract}

Keywords: Associated factors, lower Segment, caesarean section, surgical site infection.

\section{INTRODUCTION}

Surgical Site Infection (SSI) is defined as infection related to an operative procedure that occurs at or near the surgical site incision within 30 days of the procedure or within 90 days if prosthetic material is implanted at the surgical site. It is among the most common preventable complication after surgery [1]. Surgical site infection (SSI) is most common type of hospital acquired infection (HAI) in low and middle-income countries and affects one third of the patients who have undergone surgical procedures [2]. It occurs in $2-4 \%$ of all patients undergoing inpatient surgical procedures [1]. Even though most infections are treatable, SSI still remains a leading cause of prolonged hospital stay, morbidity and mortality after surgery [3]. It is also common in patients undergoing cesarean section, having history of previous cesarean section, age group above 35 years and having co-morbidities such as diabetes, obesity, anaemia etc [4].

According to World Health Organization (WHO) in low-middle income countries, the pooled incidence of SSI was 11.8 per 100 surgical procedures. According to European Centre for Disease Prevention and Control (ECDC)-SSI surveillance (2010-2011) reported cumulative incidence of $2.9 \%$ for cesarean section, where as in Africa, up to $20 \%$ of cesarean section procedure lead to SSI. Incidence of SSI per 100 procedures in USA (2014) was 1.9\%, in Europe (2013-14) 0.6-9.5\% and in South East Asia it was $7.7 \%[1,5]$. SSI leads to $38 \%$ of hospital acquired infection. Prevalence of SSI following obstetric surgeries varies from $3-15 \%$ and it is higher in cases with emergency procedure compared to elective procedures [6]. 
SSI is a preventable complication, if it is neglected it has significant burden in progress of patient condition following admission in intensive care unit, readmission and increased the cost of post discharge care. SSI is the fourth most common nosocomial infections among obstetric surgeries [7]. Since Nepal is a developing country and resources are limited, surveillance activities are important aspect in understanding its own incidence and prevalence. Thus, studies are required to identify

\section{MATERIALS AND METHODS}

\section{Study design and setting}

A retrospective cross-sectional study was conducted from 15 June 2020 to 15 September 2020 at Chitwan Medical College Teaching Hospital (CMCTH). A total of 1739 patient files who underwent Lower Segment Cesarean Section at CMCTH, from 14 $4^{\text {th }}$ April 2019 to 12 th $^{\text {April }} 2020$ were reviewed.

\section{Patients and study procedure}

All the patients who gave birth via lower segment caesarean section at Chitwan Medical College Teaching Hospital from 14 $4^{\text {th }}$ April 2019 to $12^{\text {th }}$ April 2020 were considered as the study participants. Inpatient number of all the patients underwent LSCS from 14 ${ }^{\text {th }}$ April 2019 to $12^{\text {th }}$ April 2020 were traced from Delivery Register of Gynaecology and Obstetrics department at CMCTH. Then, the patient files (medical records) were retrieved from hospital information system. Complete data regarding, demographic profile, medical and surgical history and investigations were filled in a pre-determined proforma. All files of patients who underwent Lower Segment Cesarean Section at Chitwan Medical College Teaching Hospital form 14 April 2019 to 12 April 2020 were included in the study. All files of the patients who had LSCS at other hospitals were excluded from the study.

\section{RESULTS}

Most of the patients $(90.9 \%)$ were from the age group of 20-35 years with IQR of 29 to 22, and $79.6 \%$ resided in urban area (Table 1 ). More than half $57 \%$ were primiparous, $77.9 \%$ had hemoglobin level of $\geq 11 \mathrm{gm} / \mathrm{dl}$, blood transfusion was received among $2.2 \%$, and emergency caesarean section was done on $76 \%$ of the patients (Table 2). Out of 1739 common problems and persuade others to commit to improvement. The results of this study will help to identify incidence of SSI related to obstetric surgeries and its associated factors, in order to evaluate the outcome and undertake preventive measures in near future. It also provides baseline information for hospital and guide to make improvement against this study. The aim of this study is to find out incidence and associated risk factors of SSI following obstetric surgeries.

\section{Study variables and its measurements}

Study variables includes: Dependent/ outcome Variable as: surgical site infection following lower segment cesarean Section. Independent variable includes: age, residence, parity, haemoglobin, blood transfusion and type of surgery. This study was conducted only after getting approval from Institutional Review Committee of Chitwan Medical College Teaching Hospital with reference (Ref: CMC-IRCl0761077-tI). Verbal consent for access of patient files from Hospital Information System was taken from hospital authority. All activities of this research were conducted in accordance to ethical guidelines by maintaining the confidentiality of patient data.

\section{Statistical considerations}

Data was analysed using IBM SPSS version 20 and interpreted in terms of descriptive statistics such as frequency, percentage, and median for socio demographic and clinical characteristics and information on surgical site infection. The Chisquare test (inferential statistics) was used to observe association between surgical site infection and selected variables. P-value less than 5\% was considered statistically significant for this study.

LSCS performed, 50 patients showed signs and symptoms of SSI, yielding to an infection rate of $2.9 \%$. SSI was seen in $80 \%$ of the patients after discharge, and in $40 \%$ of patients SSI had developed in $\leq 7$ of post operation day. Among swab culture of 50 SSI cases, bacteria was isolated in 6 cases only and 2 cases was evidenced with Acinetobacter and Staphylococcus aureus. (Table 3). 


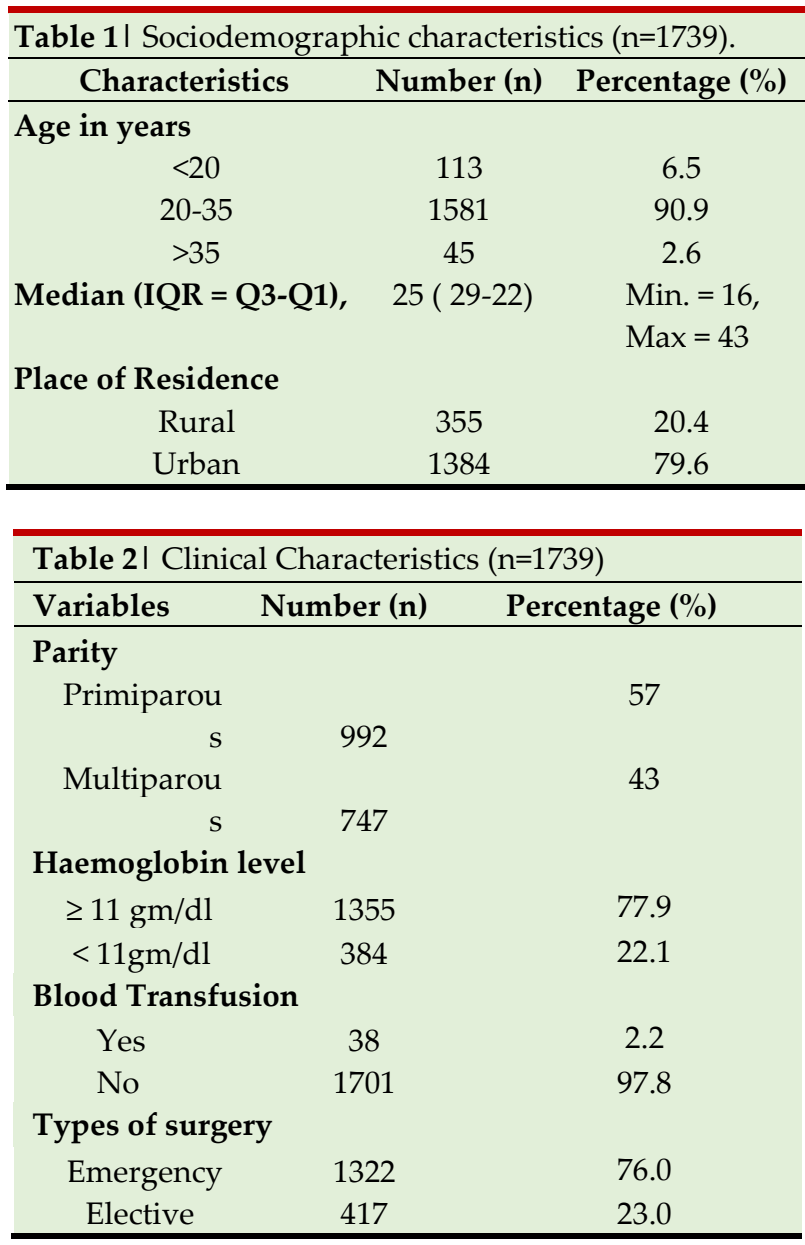

\begin{tabular}{|c|c|c|}
\hline Variables & $\begin{array}{l}\text { Number } \\
\text { (n) }\end{array}$ & $\begin{array}{l}\text { Percentage } \\
(\%)\end{array}$ \\
\hline \multicolumn{3}{|c|}{ Presence of Surgical site infection $(n=1739)$} \\
\hline Yes & 50 & 2.9 \\
\hline No & 1739 & 97.2 \\
\hline \multicolumn{3}{|c|}{ Timing of surgical site infection $(n=50)$} \\
\hline Before Discharge & 10 & 20.0 \\
\hline After Discharge & 40 & 80.0 \\
\hline \multicolumn{3}{|c|}{ Post-op day SSI Detected $(n=50)$} \\
\hline$\leq 7$ days & 20 & 40.0 \\
\hline 8-14 days & 19 & 38.0 \\
\hline$\geq 15$ days & 11 & 22.0 \\
\hline \multicolumn{3}{|c|}{ Swab Culture Report $(n=50)$} \\
\hline Positive & 6 & 12.0 \\
\hline Negative & 44 & 88.0 \\
\hline \multicolumn{3}{|l|}{ Bacteria isolated $(n=6)$} \\
\hline Acinetobacter & 2 & 33.3 \\
\hline Staphylococcus aureus & 2 & 33.3 \\
\hline Pseudomonas & 1 & 16.7 \\
\hline Klebsiella & 1 & 16.7 \\
\hline \multicolumn{3}{|c|}{$\begin{array}{l}\text { Association between surgical site infection (SSI) and } \\
\text { selected variables are shown in Table } 4 \text {. There was } \\
\text { statistically significant association between SSI and } \\
\text { types of caesarean section }(\mathrm{p}=0.007) \text {. However, SSI } \\
\text { was found insignificant for other socio } \\
\text { demographic and clinical characteristics }(\mathrm{p}>0.05) \text {. }\end{array}$} \\
\hline
\end{tabular}

\begin{tabular}{|c|c|c|c|}
\hline \multirow{2}{*}{ Variables } & \multicolumn{2}{|c|}{ Presence of SSI } & \multirow{2}{*}{ p-value } \\
\hline & Yes, n (\%) & No, n (\%) & \\
\hline \multicolumn{4}{|l|}{ Age in years } \\
\hline$<20$ & $2(1.8)$ & $111(98.2)$ & \multirow{3}{*}{0.657} \\
\hline $20-35$ & $48(3.0)$ & $1533(97.0)$ & \\
\hline$>35$ & 0 & $45(100.0)$ & \\
\hline \multicolumn{4}{|c|}{ Place of residence } \\
\hline Rural & $15(4.2)$ & $340(95.8)$ & \multirow{2}{*}{0.088} \\
\hline Urban & $35(2.5)$ & 1349 (97.5) & \\
\hline \multicolumn{4}{|l|}{ Parity } \\
\hline Primiparous & $33(3.3)$ & $959(96.7)$ & \multirow{2}{*}{0.194} \\
\hline Multiparous & $17(2.3)$ & $730(97.7)$ & \\
\hline \multicolumn{4}{|c|}{ Hemoglobin level } \\
\hline$\geq 11 \mathrm{gm} / \mathrm{dl}$ & $39(2.9)$ & 1316 (97.1) & \multirow{2}{*}{0.989} \\
\hline$<11 \mathrm{gm} / \mathrm{dl}$ & $11(2.9)$ & $373(97.1)$ & \\
\hline \multicolumn{4}{|c|}{ Blood transfusion } \\
\hline Yes & $2(5.3)$ & $36(94.7)$ & \multirow{2}{*}{0.299} \\
\hline No & $48(2.8)$ & 1653 (97.2) & \\
\hline \multicolumn{4}{|c|}{ Types of surgery } \\
\hline Emergency & $46(3.5)$ & $1276(96.5)$ & \multirow{2}{*}{$0.007^{*}$} \\
\hline Elective & $4(1.0)$ & $413(99.0)$ & \\
\hline
\end{tabular}




\section{DISCUSSION}

In the present study, the incidence of SSI was 2.9\% among women where caesarean section was performed. According to study conducted in Dulikhel Hospital, Nepal 12.6\% SSI was evidenced [8], and in tertiary care hospital of North India, 10.3 $\%$ of SSI was evidenced among patients undergoing cesarean section [9]. However, $8.1 \%$ SSI was found Debretor General Hospital, Northwest Ethiopia [10]. Thus the infection rate was far less compared to studies conducted in India, Africa and other hospitals of Nepal, might be due to inadequate tracing of cesarean section patients after discharge to identify SSI. In this study, out of 50 infected cases, $92 \%$ were observed in emergency caesarean section cases, which was consistent with the study findings of Shrestha et.al, at Dhulikhel hospital, Nepal, i.e. 90.2\% [8]. However, a study conducted in India revealed that $80.16 \%$ of SSI was evidenced in emergency caesarean section [11]. In the present study, $40 \%$ of the patients were detected with SSI within 7 days of surgical procedure, whereas $52.7 \%$ was seen in Assela teaching referral hospital, Ethiopia [6]. In regards to timing of SSI, Bizimana et al. found that $62.5 \%$ developed SSI after discharge [12], whereas, in this study $80 \%$ of patients developed SSI post-discharge. The reason behind these results might be lack of compliance or lack of healthcare professionals communicating about wound care, nutrition, and hygiene practices before discharging of patient. Out of 50 SSI patients swab collected, only 6 patients yielded positive growth. In a study done in Rwanda, out of 16 SSI patients, 14 patients showed positive microbiological culture [2]. The microbial growth was not evidenced much in this study, probably due to intake of prophylactic antibiotic before surgery and continuing till postoperative period. Chada et al. found that staphylococcus aureus was the most common bacterial isolated from patient who had undergone LSCS, followed by E Coli [13]. As per a teaching hospital in Goa, $79.33 \%$ of the isolates were gram negative bacteria, pseudomonas being the most common isolate, followed by E. coli [14]. In study conducted in china, 20 strains of bacteria including E. coli, S. aureus and P. aeruginosa were isolated from SSI cases [15]. In the present study staphylococcus 2 (33.3\%), Acinetobacter 2 (33.3\%), Klebsiella1 (16.7\%) and Pseudomonas 1(16.7\%) was observed among SSI patients. In this study there is significant association between SSI and type of surgery $(p=0.007)$ and same observation was evidenced in most of the study $[8,11]$. SSI was not statistically associated with age of patients, residence, parity, hemoglobin level and blood transfusion status. The study has some limitations: Since it is retrospective study, there is no adequate evidence to trace various causes and risk factors associated with SSI, but this study helps to provide baseline data of SSI at a teaching hospital.

home after discharge from the hospital. Thus, it is recommended that patient should be provided awareness on self-care before discharge to prevent further infection of incision site. Further studies can be done to find out the factors associated with SSI at home.

\section{ADDITIONAL INFORMATION AND DECLARATIONS}

Acknowledgment: We are thankful to Chitwan Medical College for providing study site and to staffs of Gynaecology and Obstetrics department and medical records department for helping in data collection for the study.

Funding: The authors received no funding for this work.

Competing Interests: The authors declare no competing interests.
Author Contributions: Concepts, design, literature review and data acquisition: RPSG; Data Analysis: JPS; Manuscript preparation and Editing: RPSG and RT; Intellectual content: LR; Manuscript Finalization: RPSG, LR, BT, JPS, RT

Data Availability: Data will be available up on request to corresponding authors after valid region. 


\section{REFERENCES}

1. Agency for Healthcare Research and Quality, Patient safety Network. Surgical site infections (Last updated on September 2019). Available at URL: https://psnet.ahrq.gov/primer/sur gical-site-infections

2. World Health Organization. Global guidelines for prevention of surgical site infection (Published on November 2016). Available at URL: https://www.who.int/gpsc/ssiguidelines/en/

3. National Healthcare Safety Network. Surgical site infection, Procedure associated module (Published on January 2021). Available at URL: https://www.cdc.gov/nhsn/PDFs/ pscManual/9pscSSIcurrent.pdf

4. Zejnullahu VA, Isjanovska R, Sejfija Z, Zejnullahu VA. Surgical site infections after cesarean sections at the University Clinical Center of Kosovo: rates, microbiological profile and risk factors. BMC Infect Dis. 2019 Aug 28;19(1):752. |PubMed, full text | doi: 10.1186/s12879-019-4383-7|

5. World health organization. Protocol for surgical site infection surveillance with a focus on setting with limited resources. (Published on 2018). Available at URL:

https://www.who.int/infectionprevention/tools/surgical/SSIsurveillance-protocol.pdf

6. Mamo T, Abebe TW, Chichiabellu TY, Anjulo AA. Risk factors for surgical site infections in obstetrics: a retrospective study in an Ethiopian referral hospital. Patient Saf Surg. 2017; 11:24. |PubMed, full text $\mid$ doi:10.1186/s13037-017-0138-9|

7. Gedefaw G., Asires A, Shiferaw S, Addisu D. Factors associated with surgical site infection among women undergoing obstetrics surgery at Felegehiwot Referral Hospital, Bahir Dar, Northwest Ethiopia: a retrospective crosssectional study. Saf Health. 2018;
4 (14). | Google Scholar, full text | doi:10.1186/s40886-018-0081-1।

8. Shrestha $S$, Shrestha $R$, Shrestha $\mathrm{B}$, Dongol A. Incidence and risk factors of surgical site infection following cesarean section at Dhulikhel Hospital. Kathmandu Univ Med J (KUMJ). 2014;12(46):113-6. IPubMed, Abstract I doi: 10.3126/kumj.v12i2.13656 |

9. Gupta S, Manchanda V, Sachdev P, Saini RK, Joy M. Study of incidence and risk factors of surgical site infections in lower segment caesarean section cases of tertiary care hospital of north India. Indian Journal of Medical Microbiology. 2021 Jan 1;39(1):1-5. |Google Scholar, full text | doi.org/10.1016/j.ijmmb.2020.11.00 5 I

10. Molla M, Temesgen $K$, Seyoum $T$, Melkamu M. Surgical site infection and associated factors among women underwent cesarean delivery in Debretabor General Hospital, Northwest Ethiopia: hospital based cross sectional study. BMC Pregnancy Childbirth. 2019; 29;19(1):317. |PubMed, full text | doi: 10.1186/s12884-019-2442-0 I

11. De D, Saxena $S$, Mehta G, Yadav $R$, and Dutta R, Risk factor analysis and Microbial etiology of SSI following LSCS, International Journal of Antibiotics. 2013. |Google Scholar, Full text | doi.org/10.1155/2013/283025 |

12. Bizimana JK, Ndoli J, Bayingana C, Baluhe I, Gilson GJ, Habimana E. Prevalence and risk factors for post cesarean delivery surgical site infection in a teaching hospital setting in rural Rwanda: a prospective cross-sectional study. Int J Curr Microbiol App Sci. 2016; 15;5(6):631-41. | Google Scholar, full text doi.org/10.20546/ijcmas.2016.506.0 69|

13. Chada CK, Kandati J, Ponugoti M. A prospective study of surgical site infections in a tertiary care hospital. International Surgery Journal. 2017 May 24;4(6):1945-52. |Google Scholar, full text | doi.org/10.18203/23492902.isj20172109|

14. Kamat US, Fereirra AM, Kulkarni MS, Motghare DD. A prospective study of surgical site infections in a teaching hospital in Goa. Indian Journal of Surgery. 2008 Jun;70(3):120-4. IGoogle Scholar, full text I doi: 10.1007/s12262-0080031-yl

15. Cheng K, Li J, Kong Q, Wang C, Ye N, Xia G. Risk factors for surgical site infection in a teaching hospital: a prospective study of 1,138 patients. Patient Prefer Adherence. 2015 Aug 14;9:1171-7. | PubMed, full text | doi: 10.2147/PPA.S86153| 